\title{
BMJ Open Emergency department use for mental and substance use disorders: descriptive analysis of population-based, linked administrative data in British Columbia, Canada
}

To cite: Lavergne MR, Shirmaleki M, Loyal JP, et al. Emergency department use for mental and substance use disorders: descriptive analysis of population-based, linked administrative data in British Columbia, Canada. BMJ Open 2022;12:e057072. doi:10.1136/ bmjopen-2021-057072

- Prepublication history and additional supplemental material for this paper are available online. To view these files, please visit the journal online (http://dx.doi.org/10.1136/ bmjopen-2021-057072).

Received 09 September 2021 Accepted 21 December 2021

Check for updates

(c) Author(s) (or their employer(s)) 2022. Re-use permitted under CC BY-NC. No commercial re-use. See rights and permissions. Published by BMJ.

For numbered affiliations see end of article.

Correspondence to Dr M Ruth Lavergne; ruth.lavergne@dal.ca

\section{ABSTRACT}

Objectives Information on emergency department (ED) visits for mental and substance use disorders (MSUDs) is important for planning services but has not been explored in British Columbia (BC), Canada. We describe all MSUD ED visits for people ages 15 and older in the province of BC in 2017/2018 and document trends in MSUD ED visits between $2007 / 2008$ and $2017 / 2018$ by disorder group.

Design Population-based linked administrative data comprised of ED records and physician billings capturing all MSUD ED visits in BC.

Setting BC is Canada's westernmost province with a population of approximately 5 million. Permanent residents receive first-dollar coverage for all medically necessary services provided by licensed physicians or in hospitals, including ED services.

Population All people age $>15$ with MSUD ED visits during the study period.

Measures All claims with a service location in the ED or corresponding to fee items billed only in the ED were examined alongside ED visits reported through a national reporting system. Patient characteristics (sex/gender, age, location of residence, income, treated disorders and comorbidities) and previous outpatient service use for all ED visits by visit diagnosis are also described.

Results A total of 72363 people made 134063 visits to the ED in 2017/2018 for needs related to MSUD. MSUD ED visits have increased since 2010, particularly visits for substance use and anxiety disorders. People with more frequent visits were more likely to be male, on public prescription drug plans for income assistance, prescribed psychiatric medications, and living in lower-income neighbourhoods. They used more community-based primary care and psychiatry services and had lower continuity of primary care.

Conclusions MSUD ED visits are substantial and growing in BC. Findings underscore a need to strengthen and target community healthcare services and adequately resource and support EDs to manage growing patient populations.

\section{Strengths and limitations of this study}

- Mental and substance use disorder-related emergency department (ED) visits for people ages $\geq 15$, patient characteristics, and changes in visit rates over time are comprehensively described.

- ED visits related to mental health and substance use are increasing over time, which must guide service planning.

- Combining ED records and physician claims data now permits comprehensive analysis of ED visits.

- This study is preliminary and descriptive and cannot confirm causal drivers of ED visits.

- Only one diagnosis is consistently recorded in the data, even if concurrent disorders are managed during the visits.

\section{BACKGROUND}

Accurately tracking emergency department (ED) visits related to mental and substance use disorders (MSUD) and understanding the characteristics of people with MSUD ED visits is important for service planning and improving healthcare systems. EDs provide highly accessible acute care ${ }^{12}$ and, in many cases, act as an entry point for referral to other, community-based services. ${ }^{1}$ However, unscheduled visits to care providers with little knowledge of the patient's history may limit effective patient management. ${ }^{12}$ Thus, a detailed picture of who uses the ED for MSUD-related needs and an understanding of changing ED use over time is important to plan healthcare delivery.

Internationally, literature points to increasing ED visits across varied populations and contexts. ${ }^{3-8}$ In the USA, ED visits by adults with MSUD increased by over $30 \%$ between 2006 and 2015, primarily due to alcohol use 
disorder, followed by mood and anxiety disorders. ${ }^{7}$ These findings extend earlier observation of increasing trends between 1992 and 2001. ${ }^{8}$ Similarly, in Australia, MSUD ED visits increased between 2004/2005 and 2016/2017, driven largely by psychoactive substance use, followed by anxiety and mood disorders. ${ }^{3}$ In other settings, findings differ in terms of what is driving ED use and/or the direction of changes in rates of ED use. Increases between 1988 and 2014 in Taiwan were driven by visits related to trauma and stressor-related disorders, depressive disorders, and suicide attempts. ${ }^{5}$ In contrast, in Denmark, the number of MSUD ED visits decreased from 1985 to $2012 .{ }^{6}$

Where data are available, research in Canada appears to coincide with patterns observed in the USA, with upward trends primarily reflecting increases in anxiety disorders and substance use disorders. ${ }^{9}$ However, Canadian research is limited by the fact that only a subset of ED data is collected by the national reporting system, and comparable data has not been available over time in all provinces. While many studies have examined the characteristics of people with MSUD ED visits cross-sectionally or within specific hospitals or service delivery organisations, ${ }^{10-15}$ fewer have used population-based data and examined trends over time. ${ }^{916}$

Given the variability in trends between jurisdictions within the published literature, there is value in additional localised studies. Currently, the characteristics of people visiting EDs for MSUD and trends in MSUD ED visits have not been examined in British Columbia (BC), Canada's westernmost province. This information gains added importance within the context of the overdose crisis which has disproportionately impacted BC. ${ }^{17} 18$ Our research aims to address this gap, and for the first time ever: (1) comprehensively describe all MSUD ED visits for people ages 15 and older in the province of BC, (2) describe patient and service use characteristics by number of ED visits in 2017/2018 and (3) explore changes in MSUD ED visit rates over time by disorder group (2007/2008-2017/2018).

\section{METHODS \\ Data}

We used deidentified data holdings from the BC Ministry of Health linked and made accessible through Population Data BC. ${ }^{19}$ Two data sources capture ED visits in BC: the National Ambulatory Care Reporting System (NACRS) ${ }^{20}$ and BC's Medical Services Plan (MSP) payment information. ${ }^{21}$ NACRS was developed by the Canadian Institute for Health Information to collect data on ED and other ambulatory visits. BC began reporting to NACRS in 2012 and only a subset of EDs are captured (30 of 108 BC hospitals providing ED care in 2017/2018). MSP data captures fee-for-service payments made to physicians. All EDs not reporting to NACRS are captured within the MSP data; thus, we have complete data for the entire province.

We used patient registry data, ${ }^{22}$ as well as information from hospitalisations captured through the Discharge
Abstract Database ${ }^{23}$ to describe the demographic and clinical characteristics of people with MSUD ED visits. We obtained population estimates used as denominators to construct rates of ED visits from BC Statistics. ${ }^{24}$

\section{Study population}

We examined all people ages 15+ with MSUD ED visits (diagnosis codes listed in online supplemental appendix 1) during the study period.

\section{Setting}

The province of $\mathrm{BC}$ had a population of approximately 5 million people in 2018. ${ }^{25}$ Five geographical health authorities (Fraser, Vancouver Coastal, Interior, Northern and Island) are responsible for planning and delivering healthcare services. The provincial health insurance programme (MSP) covers all permanent residents, except for a small percentage of the population covered under federal health insurance programmes. BC residents insured under MSP receive first-dollar coverage for all medically necessary services provided by licensed physicians or in hospitals, including ED services.

\section{Measures}

MSUD ED visits

We identified MSP claims with a service location in the ED or corresponding to fee items billed only in the ED (online supplemental appendix 1). We also extracted all $\mathrm{ED}$ visits to $\mathrm{BC}$ facilities recorded in NACRS data. To ensure visits were not double counted across sources or when multiple MSP claims were submitted for a single patient, we retained only one ED record per patient per day. ${ }^{26}$ Where multiple records contained different diagnoses, we retained records for MSUD. Operational definitions for frequent MSUD ED visits vary. ${ }^{1227}$ We examined individual characteristics and outpatient service use based on the following groups for annual visits, ranging from one per year to one per month, on average: $1 \mathrm{ED}$ visit, $2-5$ ED visits, 6-11 ED visits and 12+ ED visits.

\section{Demographic characteristics}

Age was obtained from BC's MSP registration file. Sex is collected at time of MSP registration. The field is labelled 'Gender' on the registration form but only the binary options ' $\mathrm{M}$ ' and ' $\mathrm{F}$ ' are provided. It is not possible to distinguish sex at birth, legal sex, and gender based on this information, so we labelled this 'sex/gender.' Health Authority was determined based on patient residential address, not location of service use. Neighbourhood income quintile was determined based on census enumeration area of residence, assigned using the Postal Code Conversion File Plus. ${ }^{28} 29$

\section{Clinical characteristics}

We classified MSUD ED visits based on disorder groupings (online supplemental appendix 2). We also examined all other MSUD services in 2017/2018. Patients with two outpatient visits or one hospitalisation (within a 365-day period) for the disorders listed in online supplemental 
appendix 2 were considered to have been treated for the disorder. ${ }^{30}$ We used this case definition as it has been validated by previous studies ${ }^{31}{ }^{32}$ and most closely aligned with expected prevalence. ${ }^{30}$ A minimum of two outpatient visits was used to be inclusive of physician consultation without ongoing care. The use of one outpatient visit overestimated the prevalence when compared with the expected prevalence for each disorder. ${ }^{30}$

In $\mathrm{BC}$, diagnostic codes for substance use disorders do not include the fifth digit, and thus it is difficult to differentiate between substances, with the exception of alcohol. We created a combined substance use disorders group (including alcohol use) within tables, but plot alcohol and other substance use separately over time .

The Charlson-Deyo Comorbidity Index categorises diagnosis codes based on 17 weighted categories. ${ }^{33} 34$ We presented both the Index's average weight and the percentage of people with no identified comorbidities based on both outpatient and inpatient service use.

\section{Health services use}

For all ED visits, we explored if people had an outpatient visit (service location office, home, or long-term care facility) with a primary care physician with an MSUD diagnosis code on the same day as the ED visit or in the preceding 30 days. We excluded visits for opioid agonist treatment (OAT, fee codes 00039 and 15039). We also determined the percentage of ED visits that subsequently resulted in hospitalisation. We identified involuntary hospitalisations under BC's Mental Health Act as those in which the patient was apprehended and admitted by police and/or if forms 4,10, 20 or 21 were on the patient's record.

For all people seen in the ED, we examined outpatient service use in the 365 days preceding their first ED visit in $2017 / 2018$. We counted the number of primary care visits occurring in the previous year (total, for MSUD and for OAT) and report the percentage of people with no visits. We calculated continuity of care over this period using the Continuity of Care Index (COCI). The COCI identifies the number of primary care physicians providing service to a patient and the percentage of care provided by each physician. The index ranges from 0 (all visits to different physicians/no visit) to 1 (all visits with one physician). In BC, primary care physicians can bill a US\$100 fee for people with Axis 1 conditions of sufficient severity to interfere with activities of daily living. The fee requires doctors to conduct a comprehensive review of the patient's history, assess the patient, and develop a treatment and management plan. ${ }^{35}$ We examined the proportion of people with a primary care mental health planning fee billed on their behalf in the 365 days preceding the ED visit as a marker of active management in primary care. We also examined number of outpatient visits (excluding visits with a hospital, day surgery or ED service location code) with a psychiatrist in the preceding year and the percentage of people with no psychiatrist visits.

\section{Analysis}

Our intention was to describe the volume of services within the system and the nature of the presenting population and so we chose to report both visit-level and patient-level information using data from 2017/2018. We first describe patient characteristics associated with each ED visit, stratified by the MSUD diagnosis associated with the visit. We report numbers and percentages or means and $\mathrm{SD}$, as appropriate, and calculated the rate of ED visits per 1000 population by health authority and income quintile.

Next, we describe the characteristics of people by number of ED visits in 2017/8. In this analysis the unit of analysis is the individual patient. We report numbers and percentages or means and SD, as appropriate.

Finally, we present ED visits per 1000 population from $2007 / 2008$ to $2017 / 2018$, stratified by disorders presenting to ED. Only visits captured in MSP data were considered in examining trends over time as NACRS data in BC were not available before 2012. We also note that $\mathrm{BC}$ fee-for-service data uses a code ' $50 \mathrm{~B}$ ' in addition to standard ICD9 codes for anxiety and depression. For this reason, it is not possible to distinguish mood and anxiety disorders in all cases. In plotting rates over time, we present this code separately for clarity.

All inferences, opinions and conclusions drawn in this article are those of the authors, and do not reflect the opinions or policies of the data stewards.

\section{Patient and public involvement}

Neither patients nor the public were involved in the design, conduct, reporting or dissemination plans of this research.

\section{RESULTS}

We observed 134063 ED visits for MSUDs in 2017/2018 across 72363 people in BC. This means roughly $1.5 \%$ of British Columbians ages 15 and older $(n=4118$ 960) used an ED for MSUD in 2017/2018. In total, 35.7\% of visits were for mood or anxiety disorders, $36.7 \%$ for substance use disorders, $7.6 \%$ for schizophrenia spectrum disorders, $5.4 \%$ for post-traumatic stress disorder (PTSD) and adjustment disorders and $14.6 \%$ for other mental disorders (eg, attention-deficit/hyperactivity disorder, eating disorders, intellectual disability, neurocognitive disorder and personality disorders) (table 1). More than half of visits for substance use and schizophrenia were among people recorded as male $(67.7 \%$ and $64.9 \%$, respectively), and more than half of visits for mood or anxiety and for PTSD and adjustment disorders were among people recorded as female (55.9\% and $53.8 \%$, respectively). More visits for other mental disorders, which include organic neurocognitive disorders, were among people aged $65+(39.2 \%)$.

Total visit rates were higher in the Northern and Interior Health Authorities (45.1 and 36.5 per 1000 population), whereas Fraser and Vancouver Coastal Health Authorities saw higher visit rates for schizophrenia spectrum 


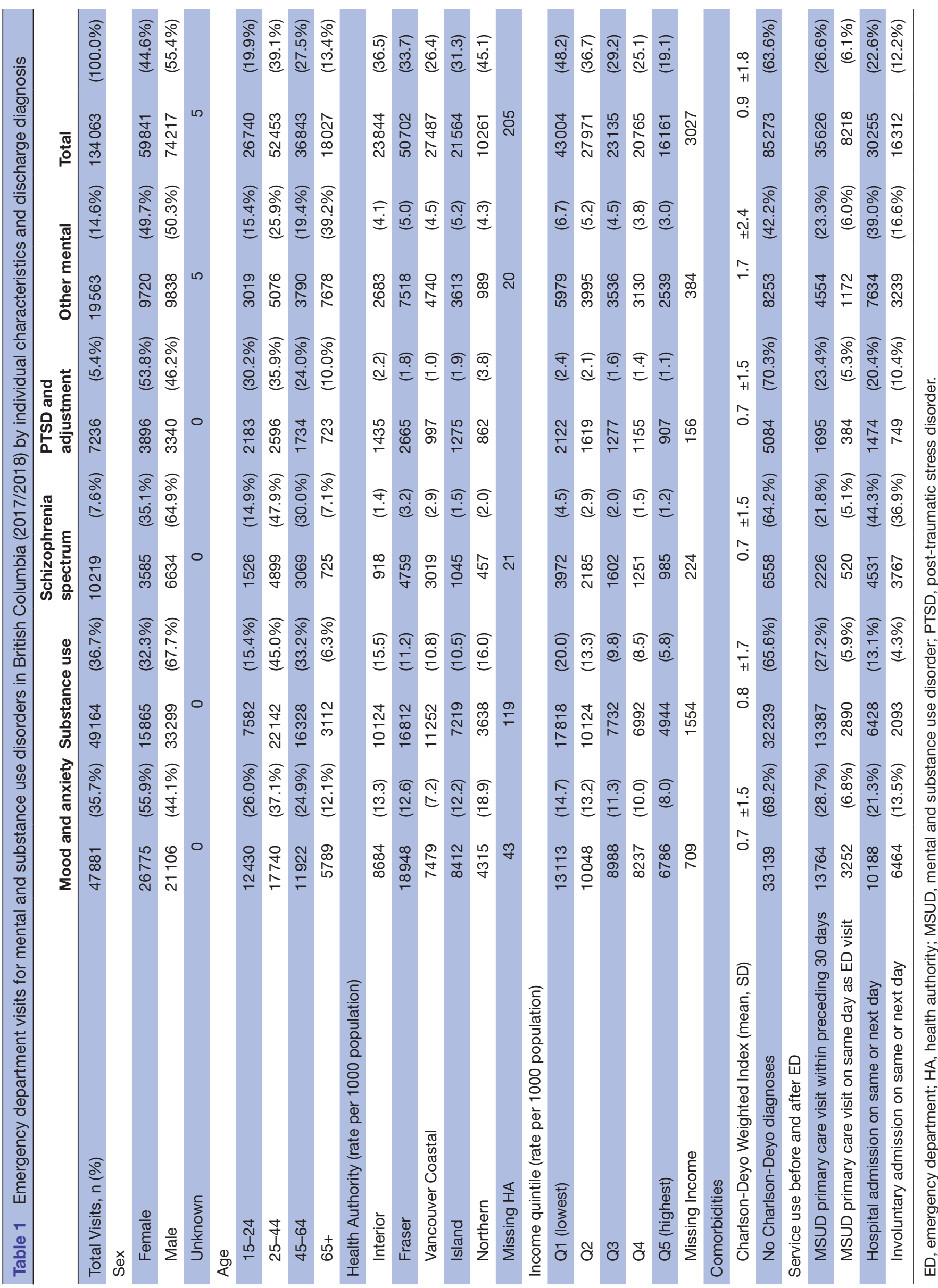




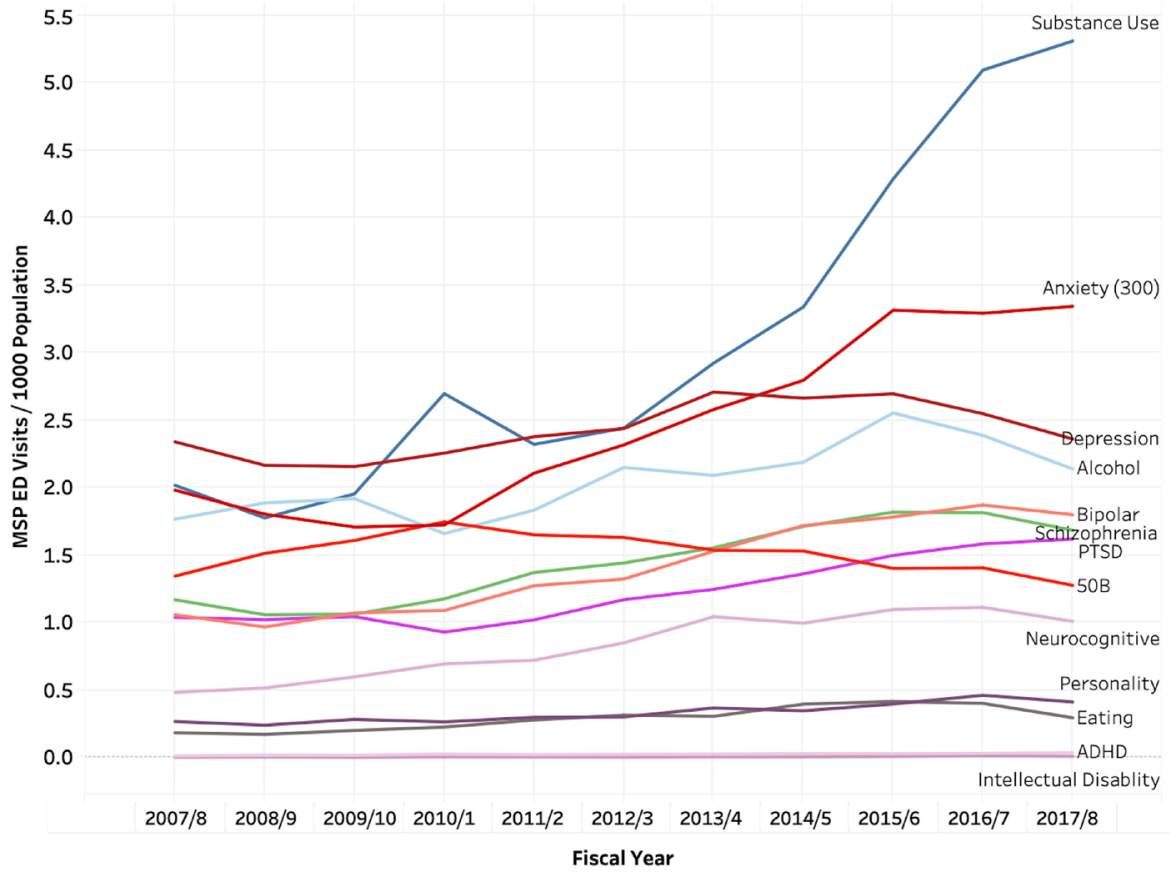

Figure 1 Rates of emergency department visits for mental and substance use disorders over time by diagnosis assigned to visit (physician claims only). ADHD, attention-deficit/hyperactivity disorder; ED, emergency department; MSP, Medical Services Plan; PTSD, post-traumatic stress disorder; 50B, diagnostic code for anxiety and depression.

disorders (3.2 and 2.9 per 1000 population) (table 1 ). Pronounced gradients by neighbourhood income were observed across all disorders. Rates of MSUD ED visits for people living in low-income neighbourhoods were more than double rates for people living in high-income neighbourhoods (48.2 vs 19.1 per 1000 population). Visits for people with substance use and schizophrenia spectrum disorders were especially high among people living in the lowest income neighbourhoods relative to the other disorders. The Charlson-Deyo Index, a measure of physical comorbidities, was similar across all groups except other mental disorders, which also had an older age distribution.

We found that $26.6 \%$ of ED visits were preceded by a primary care visit for mental health or substance use within 30 days, and $6.1 \%$ of ED visits occurred on the same day as a separate primary care visit (table 1). Across all disorders, approximately $22.6 \%$ of ED visits were followed by a hospital admission, of which more than half were involuntary admissions under BC's Mental Health Act $(12.2 \%)$. The percentage of people hospitalised was highest for schizophrenia spectrum disorders and lowest for substance use disorders for both total and involuntary hospitalisations $(44.3 \%$ and $36.9 \%$ vs. $13.1 \%$ and $4.3 \%$ ).

Rates of MSUD ED visits are increasing over time, and changes are largely driven by visits for substance use disorders, though visits for anxiety disorders also increased notably (figure 1). The percentage of people who are recorded as male, who live in metropolitan areas and in the lowest income neighbourhoods, and who have drug coverage under public Pharmacare (a marker of low-income status) all evidenced an increasing number of ED visits in 2017/2018 (table 2). The percentage of people treated for each disorder group and two or more disorders also increased with number of ED visits. Among people with 12 or more ED visits, $88.9 \%$ had been treated for a substance use disorder. The Charlson-Deyo Index of comorbidities was similar regardless of the number of ED visits. People with more ED visits also had higher mean outpatient primary care service use (all visits for MSUD and for OAT) but lower continuity of care with primary care providers (table 2). People with more ED visits also had higher mean outpatient psychiatrist visits, though overall $78.4 \%$ of people with one or more ED visits and $62.4 \%$ of people with $12+$ ED visits did not have an outpatient psychiatrist visit in the preceding year.

\section{DISCUSSION}

As expected, based on international literature, rates of ED visits for MSUD are substantial and growing, with roughly $1.5 \%$ of British Columbians ages 15 and older visiting an ED for MSUD in 2017/2018. The upward trend in ED visits largely reflects the impact of substance use and anxiety disorders as has been observed in other studies. ${ }^{379}$ High rates of comorbidity between substance use and anxiety disorders within clinical and population samples are well established. ${ }^{36}$ Symptoms of both substance use and substance use withdrawal can mimic anxiety symptoms ${ }^{36} 37$ and may be treated as anxiety. Others have proposed psychological distress, which has been increasing, is being treated as anxiety. ${ }^{38}$ Selfmedication for anxiety disorders may also be driving ED visits for substance use disorders. ${ }^{39}$ 
Table 2 Individual characteristics and outpatient service use by number of MSUD ED visits 2017/2018

\begin{tabular}{|c|c|c|c|c|c|c|c|c|c|c|}
\hline \multirow{2}{*}{ Total } & \multicolumn{2}{|c|}{1 ED visit } & \multicolumn{2}{|c|}{ 2-5 ED visits } & \multicolumn{2}{|c|}{ 6-11 ED visits } & \multicolumn{2}{|c|}{ 12+ED visits } & \multicolumn{2}{|c|}{ All people } \\
\hline & 50107 & $(69.2 \%)$ & 19353 & $(26.7 \%)$ & 2138 & (3.0\%) & 765 & $(1.1 \%)$ & 72363 & (100.0\%) \\
\hline \multicolumn{11}{|l|}{ Sex } \\
\hline Female & 24958 & $(49.8 \%)$ & 8851 & $(45.7 \%)$ & 834 & $(39.0 \%)$ & 268 & (35.0\%) & 34911 & $(48.2 \%)$ \\
\hline Male & 25149 & (50.2\%) & 10502 & $(54.3 \%)$ & 1304 & (61.0\%) & 497 & $(65.0 \%)$ & 37450 & (51.8\%) \\
\hline \multicolumn{11}{|l|}{ Age } \\
\hline $15-24$ & 11169 & (22.3\%) & 4326 & (22.4\%) & 377 & (17.6\%) & 105 & (13.7\%) & 15977 & (22.1\%) \\
\hline $25-44$ & 16625 & $(33.2 \%)$ & 7486 & $(38.7 \%)$ & 981 & $(45.9 \%)$ & 373 & $(48.8 \%)$ & 25465 & $(35.2 \%)$ \\
\hline $45-64$ & 12337 & (24.6\%) & 5073 & $(26.2 \%)$ & 639 & (29.9\%) & 253 & (33.1\%) & 18302 & (25.3\%) \\
\hline $65+$ & 9976 & $(19.9 \%)$ & 2468 & (12.8\%) & 141 & $(6.6 \%)$ & 34 & $(4.4 \%)$ & 12619 & (17.4\%) \\
\hline \multicolumn{11}{|l|}{ Health authority } \\
\hline Interior & 8797 & $(17.6 \%)$ & 2884 & $(14.9 \%)$ & 257 & $(12.0 \%)$ & 198 & $(25.9 \%)$ & 12136 & $(16.8 \%)$ \\
\hline Fraser & 17801 & (35.5\%) & 7706 & $(39.8 \%)$ & 926 & $(43.3 \%)$ & 266 & (34.8\%) & 26699 & (36.9\%) \\
\hline Vancouver Coastal & 10005 & (20.0\%) & 3916 & $(20.2 \%)$ & 481 & (22.5\%) & 175 & (22.9\%) & 14577 & (20.1\%) \\
\hline Vancouver Island & 8969 & (17.9\%) & 3245 & $(16.8 \%)$ & 324 & $(15.2 \%)$ & 88 & (11.5\%) & 12626 & (17.4\%) \\
\hline Northern & 4409 & (8.8\%) & 1577 & (8.1\%) & 147 & $(6.9 \%)$ & 38 & $(5.0 \%)$ & 6171 & (8.5\%) \\
\hline Missing & 126 & $(0.3 \%)$ & 25 & $(0.1 \%)$ & & $(0.0 \%)$ & & $(0.0 \%)$ & 154 & $(0.2 \%)$ \\
\hline \multicolumn{11}{|l|}{ Rurality } \\
\hline Metropolitan & 30734 & $(61.3 \%)$ & 12286 & (63.5\%) & 1456 & $(68.1 \%)$ & 587 & (76.7\%) & 45063 & (62.3\%) \\
\hline Small urban & 11648 & (23.2\%) & 4385 & (22.7\%) & 449 & $(21.0 \%)$ & 110 & $(14.4 \%)$ & 16592 & (22.9\%) \\
\hline Rural/remote & 7595 & (15.2\%) & 2655 & (13.7\%) & 229 & (10.7\%) & 68 & $(8.9 \%)$ & 10547 & (14.6\%) \\
\hline Unknown & 39 & $(0.1 \%)$ & 7 & $(0.0 \%)$ & & $(0.0 \%)$ & & $(0.0 \%)$ & 47 & $(0.1 \%)$ \\
\hline \multicolumn{11}{|l|}{ Neighbourhood income quintile } \\
\hline Q1 (lowest) & 13794 & $(27.5 \%)$ & 6158 & $(31.8 \%)$ & 797 & $(37.3 \%)$ & 306 & $(40.0 \%)$ & 21055 & (29.1\%) \\
\hline Q2 & 10377 & (20.7\%) & 3994 & $(20.6 \%)$ & 449 & $(21.0 \%)$ & 162 & $(21.2 \%)$ & 14982 & (20.7\%) \\
\hline Q3 & 9273 & $(18.5 \%)$ & 3403 & $(17.6 \%)$ & 345 & $(16.1 \%)$ & 111 & (14.5\%) & 13132 & (18.1\%) \\
\hline Q4 & 8610 & $(17.2 \%)$ & 3029 & $(15.7 \%)$ & 282 & $(13.2 \%)$ & 93 & $(12.2 \%)$ & 12014 & $(16.6 \%)$ \\
\hline Q5 (highest) & 7088 & $(14.1 \%)$ & 2341 & (12.1\%) & 202 & $(9.4 \%)$ & 69 & $(9.0 \%)$ & 9700 & $(13.4 \%)$ \\
\hline Missing & 965 & $(1.9 \%)$ & 428 & $(2.2 \%)$ & 63 & $(2.9 \%)$ & 24 & $(3.1 \%)$ & 1480 & $(2.0 \%)$ \\
\hline \multicolumn{11}{|l|}{ Prescription drug plan (BC Pharmacare) } \\
\hline Plan C (income assistance) & 9939 & (19.8\%) & 7012 & $(36.2 \%)$ & 1232 & $(57.6 \%)$ & 494 & $(64.6 \%)$ & 18677 & $(25.8 \%)$ \\
\hline Plan G (psychiatric medications)) & 4234 & $(8.4 \%)$ & 3543 & $(18.3 \%)$ & 476 & $(22.3 \%)$ & 168 & $(22.0 \%)$ & 8421 & $(11.6 \%)$ \\
\hline \multicolumn{11}{|l|}{ Treated disorders } \\
\hline Mood and anxiety & 20611 & $(41.1 \%)$ & 12804 & $(66.2 \%)$ & 1632 & $(76.3 \%)$ & 493 & $(64.4 \%)$ & 35540 & $(49.1 \%)$ \\
\hline Substance use & 9102 & $(18.2 \%)$ & 9423 & $(48.7 \%)$ & 1642 & $(76.8 \%)$ & 680 & $(88.9 \%)$ & 20847 & $(28.8 \%)$ \\
\hline Schizophrenia spectrum & 3159 & $(6.3 \%)$ & 4331 & $(22.4 \%)$ & 899 & $(42.0 \%)$ & 281 & $(36.7 \%)$ & 8670 & $(12.0 \%)$ \\
\hline PTSD and adjustment & 3439 & $(6.9 \%)$ & 3177 & $(16.4 \%)$ & 529 & $(24.7 \%)$ & 219 & $(28.6 \%)$ & 7364 & $(10.2 \%)$ \\
\hline Other & 7085 & $(14.1 \%)$ & 4427 & $(22.9 \%)$ & 849 & $(39.7 \%)$ & 304 & $(39.7 \%)$ & 12665 & $(17.5 \%)$ \\
\hline Two or more treated MSUDs & 10058 & $(20.1 \%)$ & 10517 & $(54.3 \%)$ & 1755 & $(82.1 \%)$ & 561 & $(73.3 \%)$ & 22891 & $(31.6 \%)$ \\
\hline \multicolumn{11}{|l|}{ Physical comorbidities } \\
\hline $\begin{array}{l}\text { Charlson-Deyo Weighted Index (mean, } \\
\text { SD) }\end{array}$ & 0.9 & \pm 1.8 & 0.8 & \pm 1.7 & 0.9 & \pm 1.7 & 1.0 & \pm 1.8 & 0.9 & \pm 1.8 \\
\hline No Charlson-Deyo diagnoses & 32815 & $(65.5 \%)$ & 12716 & $(65.7 \%)$ & 1261 & $(59.0 \%)$ & 435 & $(56.9 \%)$ & 47227 & $(65.3 \%)$ \\
\hline \multicolumn{11}{|c|}{ Outpatient service use (in 365 days preceding first ED visit in 2017/8) } \\
\hline $\begin{array}{l}\text { Primary care visits, excluding OAT } \\
\text { (mean, SD) }\end{array}$ & 8.2 & \pm 9.0 & 8.8 & \pm 9.7 & 9.6 & \pm 10.5 & 9.9 & \pm 11.9 & 8.4 & \pm 9.3 \\
\hline No primary care visits (N, \%) & 6761 & (13.5\%) & 2588 & $(13.4 \%)$ & 282 & $(13.2 \%)$ & 107 & $(14.0 \%)$ & 9738 & (13.5\%) \\
\hline
\end{tabular}


Table 2 Continued

\begin{tabular}{|c|c|c|c|c|c|c|c|c|c|c|}
\hline $\begin{array}{l}\text { MSUD primary care visits, excluding } \\
\text { methadone (mean, SD) }\end{array}$ & \multicolumn{2}{|c|}{1 ED visit } & \multicolumn{2}{|c|}{ 2-5 ED visits } & \multicolumn{2}{|c|}{ 6-11 ED visits } & \multicolumn{2}{|c|}{ 12+ED visits } & \multicolumn{2}{|c|}{ All people } \\
\hline OAT visits (mean, SD) & 1.1 & \pm 7.2 & 1.8 & \pm 8.8 & 2.5 & \pm 10.2 & 3.5 & \pm 11.8 & 1.4 & \pm 7.9 \\
\hline No OAT visits (N, \%) & 48370 & $(96.5 \%)$ & 18187 & $(94.0 \%)$ & 1943 & $(90.9 \%)$ & 592 & $(77.4 \%)$ & 69092 & $(95.5 \%)$ \\
\hline Outpatient psychiatrist visits (mean, SD) & 1.1 & \pm 4.4 & 2.2 & \pm 6.1 & 3.8 & \pm 8.5 & 3.5 & \pm 9.2 & 1.5 & \pm 5.2 \\
\hline No outpatient psychiatrist visit (N, \%) & 41704 & $(83.2 \%)$ & 13345 & $(69.0 \%)$ & 1176 & $(55.0 \%)$ & 477 & $(62.4 \%)$ & 56702 & $(78.4 \%)$ \\
\hline
\end{tabular}

$\mathrm{N}(\%)$ except where indicated.

‘The categories 'missing' and 'male' were combined in this table so as not to disclose cell sizes with fewer than five individuals.

BC, British Columbia; ED, emergency department; MSUD, mental and substance use disorder; OAT, opioid agonist treatment; PTSD, post-traumatic stress disorder.

Pronounced income gradients reflect the association between socioeconomic status and mental illness but may also suggest that EDs play a particularly important role as an access point for people living with low incomes (as indicated by low-income neighbourhoods and receiving drug coverage under public Pharmacare). This is consistent with patterns observed in cross-provincial Canadian data $^{40}$ and elsewhere. ${ }^{2} 104142$ We also observed regional variations in ED use that is likely due to differences in healthcare infrastructure and service provision. Northern Health, the least populous and geographically the largest region, saw the highest rate for ED use per 1000 population. Meanwhile, Vancouver Coastal, the region with the highest concentration of specialist services, had the lowest rate.

A recent report released by the BC Ministry of Mental Health and Addiction ${ }^{43}$ echoed and renewed calls to action $^{44} 45$ to improve MSUD services in BC. Our results are not surprising but add to the urgency of strengthening systems for MSUD service delivery. We found people with more frequent ED visits have higher use of outpatient services, indicating that existing communitybased services are not meeting people's healthcare needs. Roughly a quarter of people had a MSUD primary care visit within 30 days preceding their MSUD ED visit, suggesting people are seeking out care in the community but are unable to access care that mitigates the need for ED services. The fact that people with more frequent visits had lower continuity of care may suggest gaps in coordination and integration of outpatient services, corroborating previous research. ${ }^{46-49}$ This may also suggest primary care providers do not currently have the capacity to deliver care to help circumvent MSUD-related ED use. At the same time, well over half of people who visited the ED multiple times in the year did not have any outpatient psychiatrist visits in the year preceding their ED visit, reflecting ongoing issues accessing specialist care in the community. ${ }^{50}$ Improved integration and collaboration between primary care and specialist MSUD services could potentially address this issue, ${ }^{51}{ }^{52}$ but this has not been widely adopted in BC. Indeed, decreasing MSUD ED visits in Denmark coincided with the establishment of outpatient psychiatry clinics and specialist outreach teams. ${ }^{6}$ Alongside more integrated and collaborative treatment models, service planning efforts should focus on expanding community-based specialist care, for example, through telepsychiatry including rapid access to virtual care. ${ }^{534}$ Provision of telepsychiatry may also help reduce ED visits as observed in BC's more rural health regions by addressing regional inequities (ie, access to specialist care). ${ }^{53}$

\section{Strengths and limitations}

This study uses province-wide population-based data to, for the first time, comprehensively describe ED use for MSUDs. In the context of COVID-19, the ability to track MSUD service use and highlight potential gaps, gains additional significance. Our methods may be useful to other researchers seeking to track changing patterns of ED service use. At the same time, it is preliminary and descriptive, and thus, subject to several important limitations. Trends in diagnoses over time are based on MSP data only. The subset of facilities where fee-for-service claims are not submitted may differ in disorders seen and possibly also in changes over time. Only one diagnosis is consistently recorded in fee-for-service and NACRS data, even if concurrent disorders are managed during the visits. This may lead to under-detection of substance use disorders in particular, as has been observed in validation studies. ${ }^{55}$ People with certain mental disorders (eg, schizophrenia) and substance use disorders are at high risk of experiencing violence ${ }^{5657}$ and may also seek out ED services accordingly. These visits are not likely to capture the underlying MSUD and thus will not be recorded in our data. Similarly, visits for self-injurious behaviours due to substance use ${ }^{58}$ do not likely capture the underlying substance use disorder. We cannot confirm causal drivers 
of increasing rates of ED visits for substance use disorders and anxiety disorders.

\section{Conclusion}

The use of ED services for MSUD is substantial and growing in BC. While substance use disorders largely accounts for increasing rates over time, visits for anxiety disorders and other conditions are also increasing. Findings underscore the urgent need to strengthen and target community healthcare services for people who remain poorly served, and to adequately resource and support EDs to manage growing and changing patient populations.

\section{Author affiliations}

${ }^{1}$ Department of Family Medicine, Dalhousie University Faculty of Medicine, Halifax, Nova Scotia, Canada

${ }^{2}$ Centre for Applied Research in Mental Health and Addiction, Simon Fraser University, Vancouver, British Columbia, Canada

${ }^{3}$ British Columbia Centre for Disease Control, Vancouver, British Columbia, Canada ${ }^{4}$ Department of Psychiatry, The University of British Columbia Faculty of Medicine, Vancouver, British Columbia, Canada

${ }^{5}$ Department of Psychology, Simon Fraser University, Burnaby, British Columbia, Canada

${ }^{6}$ British Columbia Mental Health and Substance Use Services, Vancouver, British Columbia, Canada

${ }^{7}$ Centre for Health Evaluation and Outcome Sciences, The University of British Columbia, Vancouver, British Columbia, Canada

${ }^{8}$ Faculty of Health Sciences, Simon Fraser University, Burnaby, British Columbia, Canada

${ }^{9}$ School of Criminal Justice and Criminology, Texas State University San Marcos, San Marcos, Texas, USA

${ }^{10}$ School of Population and Public Health, The University of British Columbia, Vancouver, British Columbia, Canada

${ }^{11}$ British Columbia Centre on Substance Use, Vancouver, British Columbia, Canada

Contributors MRL planned analysis and led drafting of the manuscript. MS conducted analysis of linked data, including development of methods for capturing ED visits. JPL contributed to conception of the paper and literature review. WJ, TLN, CGS, AV, HS, JHP, RK and MK all contributed to planning analysis, interpreting findings and made critical revisions to the manuscript. WS oversaw all aspects of this study and assisted in interpretation of findings. All authors approved this version of the paper and agree to act as guarantors of this research.

Funding This work was supported by the Canadian Institutes of Health Research and the Michael Smith Foundation for Health Research (Partnerships for Health System Improvement grant number FRN-148170).

Disclaimer The funders had no role in the design of the study or in the data analysis and interpretations, nor were they involved in the writing of the manuscript.

Competing interests The authors have no relevant financial or non-financial interests to disclose. Dr. M Ruth Lavergne receives salary support from a Tier II Canada Research Chair in Primary Care and Dr. Joseph Puyat receives salary support from a Michael Smith Foundation for Health Research Scholar Award.

Patient consent for publication Not applicable.

Ethics approval This study was approved by the University of British Columbia, Providence Health Care Research Institute, and Simon Fraser University research ethics boards (REB number H17-00506).

Provenance and peer review Not commissioned; externally peer reviewed.

Data availability statement Data may be obtained from a third party and are not publicly available. Linked, deidentified data holdings from the BC Ministry of Health linked and made accessible through Population Data BC were used for analysis. We are not permitted to share the research extract used in this analysis with other researchers, but all data are available through Population Data BC. All inferences, opinions and conclusions drawn in this article are those of the authors, and do not reflect the opinions or policies of the data stewards.

Supplemental material This content has been supplied by the author(s). It has not been vetted by BMJ Publishing Group Limited (BMJ) and may not have been peer-reviewed. Any opinions or recommendations discussed are solely those of the author(s) and are not endorsed by BMJ. BMJ disclaims all liability and responsibility arising from any reliance placed on the content. Where the content includes any translated material, BMJ does not warrant the accuracy and reliability of the translations (including but not limited to local regulations, clinical guidelines, terminology, drug names and drug dosages), and is not responsible for any error and/or omissions arising from translation and adaptation or otherwise.

Open access This is an open access article distributed in accordance with the Creative Commons Attribution Non Commercial (CC BY-NC 4.0) license, which permits others to distribute, remix, adapt, build upon this work non-commercially, and license their derivative works on different terms, provided the original work is properly cited, appropriate credit is given, any changes made indicated, and the use is non-commercial. See: http://creativecommons.org/licenses/by-nc/4.0/.

\section{ORCID iD}

Jackson P Loyal http://orcid.org/0000-0002-0397-4498

\section{REFERENCES}

1 Wise-Harris D, Pauly D, Kahan D, et al. "Hospital was the only option": experiences of frequent emergency department users in mental health. Adm Policy Ment Health 2017;44:405-12.

2 Fleury M-J, Grenier G, Farand L, et al. Use of emergency rooms for mental health reasons in Quebec: barriers and facilitators. Adm Policy Ment Health 2019;46:18-33.

3 Tran QN, Lambeth LG, Sanderson K, et al. Trend of emergency department presentations with a mental health diagnosis in Australia by diagnostic group, 2004-05 to 2016-17. Emerg Med Australas 2020;32:190-201.

4 Benarous X, Milhiet V, Oppetit A, et al. Changes in the use of emergency care for the youth with mental health problems over decades: a repeated cross sectional study. Front Psychiatry 2019;10:26

5 Chen W-H, Hsieh MH, Liao S-Cet al. A quarter of century after: the changing ecology of psychiatric emergency services. Asia Pac Psychiatry 2021;42:e12487.

6 Moltke K, Høegh EB, Sæbye D, et al. Psychiatric emergency services in Copenhagen 2012: a 27-year psychiatric and demographic followup study. Nord J Psychiatry 2015;69:1741-7.

7 Nam E, Lee E, Kim H. 10-Year trends of emergency department visits, wait time, and length of stay among adults with mental health and substance use disorders in the United States. Psychiatr $Q$ 2021:92:1159-74.

8 Larkin GL, Claassen CA, Emond JA, et al. Trends in U.S. emergency department visits for mental health conditions, 1992 to 2001. PS 2005:56:671-7.

9 Chiu M, Gatov E, Vigod SN, et al. Temporal trends in mental health service utilization across outpatient and acute care sectors: a population-based study from 2006 to 2014. Can J Psychiatry 2018;63:94-102.

10 Doupe MB, Palatnick W, Day S, et al. Frequent users of emergency departments: developing standard definitions and defining prominent risk factors. Ann Emerg Med 2012;60:24-32.

11 Kendall CE, Boucher LM, Mark AE, et al. A cohort study examining emergency department visits and hospital admissions among people who use drugs in Ottawa, Canada. Harm Reduct $J$ 2017;14:16.

12 Vandyk AD, Harrison MB, VanDenKerkhof EG, et al. Frequent emergency department use by individuals seeking mental healthcare: a systematic search and review. Arch Psychiatr Nurs 2013;27:171-8.

13 Hynie M, Ardern Cl, Robertson A. Emergency room visits by uninsured child and adult residents in Ontario, Canada: what diagnoses, severity and visit disposition reveal about the impact of being uninsured. J Immigr Minor Health 2016;18:948-56.

14 Chambers C, Chiu S, Katic M, et al. High utilizers of emergency health services in a population-based cohort of homeless adults. Am $J$ Public Health 2013;103:S302-10.

15 Saunders NR, Gill PJ, Holder L, et al. Use of the emergency department as a first point of contact for mental health care by immigrant youth in Canada: a population-based study. Can Med Assoc J 2018:190:E1183-91.

16 Newton AS, Rosychuk RJ, Dong K, et al. Emergency health care use and follow-up among sociodemographic groups of children who visit emergency departments for mental health crises. CMAJ 2012;184:E665-74.

17 Krausz RM, Westenberg JN, Ziafat K. The opioid overdose crisis as a global health challenge. Curr Opin Psychiatry 2021;34:405-12. 
18 Belzak L, Halverson J. Evidence synthesis - The opioid crisis in Canada: a national perspective. Health Promot Chronic Dis Prev Can 2018;38:224-33.

19 Population Data BC. The data linkage process. Available: https:// www.popdata.bc.ca/datalinkage/process

20 Canadian Institute for Health Information. National ambulatory care reporting system metadata (NACRS), 2017-2018, 2019. Available: http://www.popdata.bc.ca/data

21 British Columbia Ministry of Health. Medical services plan (MSP) payment information file, 2019. Available: http://www.popdata.bc.ca/ data

22 British Columbia Ministry of Health. Consolidation file (MSP registration \& premium billing), 2018. Available: http://www.popdata. bc.ca/data

23 Canadian Institute for Health Information. Discharge abstract database, 2018. Available: http://www.popdata.bc.ca/data

24 British Columbia Statistics. Sub-provincial population projections P.E.O.P.L.E, 2018. Available: https://www.bcstats.gov.bc.ca/apps/ PopulationProjections.aspx

25 British Columbia Statistics. British Columbia population estimates: annual population, July 1, 1867-2019, 2021. Available: https://www2. gov.bc.ca/assets/gov/data/statistics/people-population-community/ population/pop_bc_annual_estimates.csv

26 Peterson S, Wickham M, Lavergne R. Methods to comprehensively identify emergency department visits using administrative data in British Columbia. Vancouver, BC: UBC Centre for Health Services and Policy Research, 2021. https://www.popdata.bc.ca/sites/default/ files/documents/data\%20access/methodological/CHSPR-EDReport-2021.pdf

27 Moe J, Bailey AL, Oland R, et al. Defining, quantifying, and characterizing adult frequent users of a suburban Canadian emergency department. CJEM 2013;15:214-26.

28 Wilkins R. Use of postal codes and addresses in the analysis of health data. Health Rep 1993;5:157.

29 Wilkins R. Automated geographic coding based on the statistics Canada postal code conversion files, including postal codes through March 2009. Ottawa: Analysis Division, Statistics Canada, 2009.

30 Jones W, Kaoser R, Samji H. Identifying mental and substance use disorders using administrative data. Centre Appl Res Mental Health Addict 2020.

31 Frayne SM, Miller DR, Sharkansky EJ, et al. Using administrative data to identify mental illness: what approach is best? Am J Med Qual 2010;25:42-50.

32 Kisely S, Lin E, Lesage A, et al. Use of administrative data for the surveillance of mental disorders in 5 provinces. Can J Psychiatry 2009;54:571-5

33 Deyo R, Cherkin DC, Ciol MA. Adapting a clinical comorbidity index for use with ICD-9-CM administrative databases. J Clin Epidemiol 1992;45:613-9.

34 Quan H, Sundararajan V, Halfon P, et al. Coding algorithms for defining comorbidities in ICD-9-CM and ICD-10 administrative data. Med Care 2005;43:1130-9.

35 Doctors of British Columbia. Mental health fees, 2020. Available: https://gpscbc.ca/sites/default/files/uploads/GPSC-Mental-HealthBilling-Guide-20210101.pdf

36 Grant BF, Stinson FS, Dawson DA, et al. Prevalence and cooccurrence of substance use disorders and independent mood and anxiety disorders: results from the National epidemiologic survey on alcohol and related conditions. Arch Gen Psychiatry 2004;61:807-16.

37 Vorspan F, Mehtelli W, Dupuy G, et al. Anxiety and substance use disorders: co-occurrence and clinical issues. Curr Psychiatry Rep 2015;17:4.

38 Baxter AJ, Scott KM, Ferrari AJ. Challenging the myth of an "epidemic" of common mental disorders: Trends in the global prevalence of anxiety and depression between 1990 and 2010: depress anxiety 2014;31:506-16.

39 Robinson J, Sareen J, Cox BJ, et al. Role of self-medication in the development of comorbid anxiety and substance use disorders: a longitudinal investigation. Arch Gen Psychiatry 2011;68:800-7.
40 Canadian Institute for Health Information. Common challenges, shared priorities: measuring access to home and community care and to mental health and addictions services in Canada. Ottawa, ON: CIHI, 2019. https://www.cihi.ca/sites/default/files/document/shpcompanion-report-en.pdf

41 Urbanoski K, Inglis D, Veldhuizen S. Service use and unmet needs for substance use and mental disorders in Canada. Can J Psychiatry 2017;62:551-9.

42 Fleury M-J, Grenier G, Bamvita J-M, et al. Typology of patients who use emergency departments for mental and substance use disorders. BJPsych Open 2020;6:e59.

43 BC Ministry of Mental Health and Addictions. A pathway to hope: a roadmap for making mental health and addictions care better for people in British Columbia, 2019. Available: https://www2.gov.bc $\mathrm{ca} /$ assets/gov/british-columbians-our-governments/initiatives-plansstrategies/mental-health-and-addictions-strategy/bcmentalhealthro admap_2019web-5.pdf

44 Canadian Alliance on Mental, IIIness and Mental Health. A call for action: building consensus for a national action plan on mental illness and mental health. Ottawa, 2000. Available: https://mdsc.ca/ documents/Publications/A\%20call\%20for\%20action_EN.pdf

45 BC Ministry of Health Services and BC Ministry of Children and Family Development. Healthy minds, healthy people - A 10-year plan to address mental health and substance use in British Columbia, 2010. Available: https://www.health.gov.bc.ca/library/publications/ year/2010/healthy_minds_healthy_people.pdf

46 Colligan EM, Pines JM, Colantuoni E, et al. Factors associated with frequent emergency department use in the Medicare population. Med Care Res Rev 2017;74:311-27.

47 Marshall EG, Clarke B, Burge F, et al. Improving continuity of care reduces emergency department visits by long-term care residents. $J$ Am Board Fam Med 2016;29:201-8.

48 McCusker J, Tousignant P, Silva RBD, et al. Factors predicting patient use of the emergency department: a retrospective cohort study. Can Med Assoc J 2012;184:E307-16.

49 Ionescu-Ittu R, McCusker J, Ciampi A, et al. Continuity of primary care and emergency department utilization among elderly people. Can Med Assoc J 2007;177:1362-8.

50 Goldner EM, Jones W, Fang ML. Access to and waiting time for psychiatrist services in a Canadian urban area: a study in real time. Can J Psychiatry 2011;56:474-80.

51 Fleury M-J, Imboua A, Aubé D, et al. General practitioners' management of mental disorders: A rewarding practice with considerable obstacles. BMC Fam Pract 2012;13:1-12.

52 Jego M, Debaty E, Ouirini L, et al. Caring for patients with mental disorders in primary care: a qualitative study on French GPs' views, atittudes and needs. Fam Pract 2019;36:72-6.

53 Fortney JC, Pyne JM, Turner EE, et al. Telepsychiatry integration of mental health services into rural primary care settings. Int Rev Psychiatry 2015;27:525-39.

54 Costanza A, Mazzola V, Radomska M, et al. Who consult an adult psychiatric emergency department? pertinence of admissions and opportunities for telepsychiatry. Medicina 2020;56:295.

55 Wang L, Homayra F, Pearce LA, et al. Identifying mental health and substance use disorders using emergency department and hospital records: a population-based retrospective cohort study of diagnostic concordance and disease attribution. BMJ Open 2019;9:e030530.

56 Khalifeh H, Dean K. Gender and violence against people with severe mental illness. Int Rev Psychiatry 2010;22:535-46.

57 Darke S, Torok M, Kaye S, et al. Attempted suicide, self-harm, and violent victimization among regular illicit drug users. Suicide Life Threat Behav 2010;40:587-96.

58 Costanza A, Rothen S, Achab S, et al. Impulsivity and impulsivityrelated endophenotypes in suicidal patients with substance use disorders: an exploratory study. Int J Ment Health Addict 2021;19:1729-44. 